\title{
Mapping trends and framing issues in higher music education: Changing minds/changing practices
}

\author{
Helen Julia Minors* \\ Kingston University \\ Pamela Burnard \\ University of Cambridge \\ Charles Wiffen \\ Bath Spa University \\ Zaina Shihabi \\ Liverpool Hope University \\ J. Simon van der Walt \\ Royal Conservatoire of Scotland
}

\begin{abstract}
This article presents five case studies from within music in higher education programmes that collectively explore key questions concerning how we look at the challenges and trends, and the need for change to react to the recent higher education (HE) climate, through reference to teaching musicians the skills, knowledge and diverse career creativities that are valued in preparing musicians to enter sustained careers. In this article, the National Association for Music in Higher Education (NAMHE) elected committee members explore the emerging issues and agendas within the context of higher education, and the national and international policy shifts that are occurring. The case studies explore: (I) an inclusive curriculum and undergraduate student partner project; (2) employability skills and postgraduate courses; (3) digital creativities; (4) music career creativities and gender; and (5) an integrated student experience.
\end{abstract}

Keywords: higher music education; creativity; inclusion; training professional musicians; digital technologies

\section{Imperatives for the employability of new graduates}

Training musicians for the twenty-first century requires a strategy to ensure graduate success: institutions aspire for students to achieve a good degree (defined in the UK as a first-class or upper second-class degree classification) by equipping graduates with flexible, innovative, professional skills that will ensure they can survive in an ever-changing, digitized, competitive international environment. The music industry, like the higher education (HE) landscape, is changing fast, and staff and students alike must keep abreast of these changes in order to provide a relevant and valuable educational experience. In a harshly competitive environment, which has seen a number of music departments in the UK close in recent years (Taylor, 20I5: I I4), we

* Corresponding author - email: h.minors@kingston.ac.uk

(C) Copyright 2017 Minors, Burnard, Wiffen, Shihabi and van der Walt. This is an Open Access article distributed under the terms of the Creative Commons Attribution Licence, which permits unrestricted use, distribution and reproduction in any medium, provided the original author and source are credited. 
must strive for excellence in all we do, while maintaining advocacy for the benefit of what we do to an audience beyond ourselves and students. The value of a music degree is far reaching, encompassing not only music-specific skills, but a variety of transferable skills: communication skills, management skills - skills that are highly sought after by employers (NAMHE, 2015-16; RMA, 20I6a; RMA, 20I6b, RMA, 2016c; RMA, 20I6d; RMA, 2016e).

The purpose of this co-authored article is to explore some key questions concerning how we train undergraduate and postgraduate musicians within higher music education. We explore examples of teaching the skills, knowledge and diverse creativities that are valued in preparing musicians to enter varied types of careers, alongside examples that advocate for equality, diversity and inclusion. In referring to diverse creativities, we speak to recent literature that has called for the need to expand the notion of creativity to 'embrace the world of the internet' (Burnard, 20I4: 3) and to respond to the challenges of the contemporary music industry by incorporating creativities that are 'characterized by fast moving change, the imperative for networking and innovation, and the necessity of being able to negotiate cultural differences' (Gaunt and Westerlund, 20I6: I). As Burnard (20I4: xxvi) notes, 'being creative $\ldots$ is an imperative' for developing skills ready for the creative industries. The co-authors are all current, or former, elected executive committee members of the National Association for Music in Higher Education (NAMHE), representing a range of UK institutions (including the 24 Russell Group institutions, which are research-intensive, the newer post-1992 institutions, and the conservatoires, which are dedicated to professional practice and performance), as well as spanning a range of academic posts (professorial, management, teaching-research and doctoral candidate). The co-authors collaborated on presentations at the annual conference of the International Society for Music Education in Glasgow in July 2016, discussions from which were the origin of this article (Minors et al., 2016). Together we explore and debate the emerging issues within the context of $\mathrm{HE}$, concerning an inclusive and diverse curriculum, embedding employability skills and utilizing digital technologies in teaching and learning, and the national and international policy shifts that are occurring (including the newly formed Teaching Excellence Framework (TEF) and the Office for Students, which will assess teaching quality and set fees through newly established processes (HEFCE, n.d.)).

We provide five new illustrative case studies from which to iterate some of the key concerns within the discipline, encompassing:

(I) the integration of practical creativities within an inclusive music curriculum to identify the strength and benefit of teaching through creative practice and collaboration, notably referring to diversity and inclusion, and significantly to the role of student partners (SP) and to the distributed leadership of staff and students working in such partnerships (with reference to the funded project, 'Taking Race Live' (TRL), conducted at Kingston University from 2014)

(2) the role of employability skills, resilience and adaptability within the postgraduate curriculum to train future professional musicians (with reference to postgraduate curriculum design at the Royal Scottish Conservatoire (20l4)

(3) the importance of digital creativity and the use of online research resources, which are now embedded within the music curriculum (with reference to digital collaboration within distance learning MA programmes at Bath Spa University)

(4) the imperative for institutional change regarding gender and equality (with reference to a NAMHE-commissioned research project, 'Gender Equality in Music Higher Education' (Bogdanovic, 20I5)) 
(5) the pervasive notion of an integrated student experience and the use of social media within HE (with reference to student focus groups conducted at Liverpool Hope University in 2016).

To further understand and enact diverse creativities (including collaborative learning, digital practices, intercultural engagement and innovative approaches) within the HE music sector, we share these five new case studies below.

\section{Inclusive curriculum and changing disciplinary boundaries}

The range and breadth of music degrees in HE in the UK are vast (Kingston University 2016a; Kingston University 2016b; Kingston University 2016c). Often challenging disciplinary borders, there are significant questions regarding the diversity of the subject: in advocating for continued diversity and breadth of the field, it is necessary also to develop an inclusive curriculum that recognizes students' prior learning and experiences, and enables them to see themselves in the curriculum. Recent national protest and Students' Union activism have seen valid questions raised and debated publicly, such as in the campaign established at University College London, 'Why is my curriculum white?' (Hussain, 20I5) and questions such as 'Why is my professor still not black?' (Morgan, 2016). This campaign sought to question how the celebration of diversity in HE remained under-represented in the curriculum taught.

There is a nationally recognized attainment gap between students, notably between white students and black, Asian and ethnic minority students (often referred to as BAME) (see Berry and Loke, 20I I). Taking a lead to remove this attainment gap and to ensure equality, diversity and inclusion, Kingston University has set a Key Performance Indicator (KPI) concerning the attainment gap. This KPI is assessed via the 'value added' score, using a prediction of students' potential (based on their prior achievements) to determine what their potential exit award might be (Kingston University, 2016).

Tackling inclusion in the curriculum, and seeking to enhance the student experience by integrating opportunities for wider networking challenges within and beyond the classroom, and the inclusion of social and digital media (as outlined as essential to creative music learning by Gaunt and Westerlund, 2016), the project 'Taking Race Live' (TRL) was launched. Established in 20I4, working across sociology (20I4 and ongoing, established by Sonya Sharma, with Sylvia Collins-Mayo, and joined by Heidi Seetzen in 2016), drama (2014-15, with Jackie Smart), music (from 2015 and ongoing, with Helen Julia Minors), television and dance (2016-17, with Colette Balmain and Elena Catalano), the project has sought to work with student partners (SP) to enhance the curriculum by utilizing students' voices in planning activities, events and external trips. Six SPs were employed in 2014/15 and 2015/16; then eight SPs were employed as we expanded the reach of the project in 2016/17.

The project links second-year modules across these subjects ('Aural, Analysis and Improvisation' and 'Researching Race and Ethnicity'). The project relies on SPs, who are appointed via interview and remunerated via an honorarium. This approach aims to remove staff hierarchy in project meetings, seeking to place everyone's experiences as equal. TRL works on the principle of liveness, a concept relevant to both music (Auslander, 1999) and sociology (Back and Puwar, 2012; Puwar, 2004): it seeks to use live experiential methods to explore personal and collective experiences to supplement classroom learning. As SPI (2015) confirmed, 'it was an amazing opportunity for everyone to voice their experiences'. TRL questions the nature of the live experience within a mediatized culture and provokes critical self-reflection through a reassessment of students' expectations, knowns and realizations, as explored through the 
project. As SP4 (2016) observed, 'I developed a talent that l'm trying to express myself through music ... as part of a culture ... [while] trying to analyse, from outside, what we do.'

This distributed leadership (whereby all members of the committee take responsibility for the project equally) resulted in trips to the Young Vic to see A Man of Good Hope (2016); to the Royal Festival Hall to see Under the Skin (2017); to the Black Cultural Archives exhibition Black Georgians: The shock of the familiar (2016); to Tate Britain's challenging Britain and Empire (2016) and to Syd Shelton: Rock against racism (2015). How did these events benefit the students' experience? SP2 (2016) saw benefit in the pop-up events as 'it gave us the chance to speak to other students' beyond their modules. Notably, all events interrogated identity within times of change: each had a reach beyond the local, to a wider national and international outlook. Students were encouraged to question their own experiences of the performances and exhibitions, and to raise questions with their peers. The creative response of the students was notable.

Students created new music in response to the Tate Britain exhibition and lyrics in response to the Black Cultural Archives. For example, in response to Walter Crane's Imperial Federation Mapp (1886), SP6 created an instrumental piece that explored the interplay of musical styles to represent the journeys of peoples across the globe. Using a motivic idea, the work progressed in sections, modifying the rhythmic, harmonic and instrumental setting of the ideas as an analogy to the different cultural contexts represented on the map. The motif, unifying the monothematic work, subtly projected the unifying feature of the map. This musical work was presented at the 2016 symposium, taking creative work out from the classroom, and from assessment, to a wider public audience. The self-development formed from new networks and collaborative working, through to managing and presenting events, was viewed positively: SP3 (2016) claimed, 'it's definitely going to help in the future because of that personal development', while SP2 (2016) recognized 'how to follow through on research' in creating a public event.

Other student-led events were hosted. The final symposia, TRL: 'Sounds of Race and Culture' (April 2016) and 'Spaces of Race and Culture' (April 2017) brought together performances from music students, set beside a performance by the Kingston University alumni musician Yazz Ahmed and her Quartet (20I6), with student-dramatized responses to written pieces by sociology students, as well as keynote addresses. Notably, chosen collectively by the steering committee, Professor Paul Gilroy (2016) presented on the theme of race and culture via an engaging, critical and reflective presentation on music in Brixton over six decades, while Nirmal Puwar (2017) shared her sociological view of liveness.

The outcomes of the project were not assessed through summative means in addition to the usual module assessment; rather, focus groups were conducted and qualitative-quantitative analysis produced. Recently, a filmed interview between the project partners, exploring what the benefits of the project have been, has been released (Inclusive Curriculum, 2017). Key issues arose in the qualitative analysis that have affinity with the core aims of the project and to key concerns for music in HE institutions, notably, the enhancement of the student experience, student participation, student confidence and student employability. The following responses are taken from the student focus group, which recorded the discussion of the six appointed SPs (2016).

In summarizing their overall experience of the project and their role as SPs, reference was made to a 'refreshed enjoyment' in their studies (SP5, 2016) due to a sense of being included in something they identified as significant. Confidence building was a notable issue raised in student feedback: 'I never thought I could succeed' (SP5, 20I6). SP5 not only led some of the activities, but also presented verbally in front of a large audience, overcoming her anxiety regarding her learning difficulties. This student gained a high first-class mark in the final assessment, after starting the year considering withdrawal from university. 
Regarding their shared experiences, the feedback from both music and sociology students revealed recognition of the experiences of others: 'I kind of put myself in their shoes' (SPI, 20I6); 'I lent myself to the painting, and it gave something back to me, changing my perspective' (SP6, 2016). The ways in which the experiences of the project changed students' expectations and understandings was unanimously seen as a positive outcome of the project. In the enhancement of students' learning, the range of events was acknowledged: 'I think a lot of people appreciated the symposium because it's different to any other events or lecture, guest lectures that we have in uni. And it gives people from different ethnic backgrounds, as well, the opportunity to embrace their culture' (SP2, 2016). Realization was iterated regarding how collaboration fosters creativity within a cultural and political context: '[we] were a bit more open-minded about what is race and why does it have a huge impact in politics and music' (SP4, 2016). Recognition of the project's impact has come in various forms: the project team won the Rose Award for 'Learning, Teaching and Assessment, Research' (2016), the project has been nominated by the Higher Education Academy for a Collaborative Award in Teaching Excellence (2017), and the project was used as a case study for the HEFCE report, Causes of Differences in Student Outcomes (Mountford-Zimdars et al., 20I5). As Berry and Loke noted, 'the national attainment gap between BME students and white students was 18.3\%' (20II: 9); TRL demonstrated a significant impact on this gap by removing it from both modules involved in the project. All those engaging as SPs in the first year gained good degrees (first-class or upper second-class degrees); those students participating in the second year of the project gained first-class or upper second-class marks within the connected modules. The longitudinal project is in its third year, now in expanded collaboration between music, sociology, dance and television. The project has supported better student engagement, enhanced student experience and contributed to developing an inclusive curriculum. In responding proactively to trends in $\mathrm{HE}$ that seek to ensure an inclusive curriculum and a fair experience for all, this project not only sought to reduce the attainment gaps, but also to enhance students' experience by engaging students beyond the classroom in activities and events that were relevant to their wider learning. Utilizing module-level data concerning attainment and progression, it was possible to analyse the impact of the project, run in its first year, and to take new actions for the following years of the project in music in 2016/17.

\section{Critical artistry}

Employment statistics for graduates of music programmes are extraordinarily strong. Taking as an example the programme for which van der Walt has responsibility at the Royal Conservatoire of Scotland, as the prospectus proudly states, ' $89 \%$ of MMus students are in employment or further study' and ' $100 \%$ of MMus Opera graduates are in employment or further study' (Royal Conservatoire, 2016: 37-46). Both these claims are based on Higher Education Statistics Agency figures and are doubtless accurate in so far as they go.

Statistics mask individual stories: when it became known that one of the graduates from the Royal Conservatoire of Scotland MMus Repetiteur programme had reported being unemployed, it was difficult to reconcile. How could it be that a student who had the talent and tenacity to survive such a specialized programme was unable to find work at all, and in a field where only one or two graduates would be produced in Scotland in any one year? Were students encouraged to over-specialize? But as the Musicians' Union notes: 'There is no such thing as a typical musician. ... Developing a portfolio career ... is a necessary characteristic of many musicians' careers; this invariably involves developing non-music skills such as business, marketing, teaching and community engagement' (20I2: 5). 
In 2013, the Royal Conservatoire of Scotland undertook a review of all of its second-cycle taught postgraduate programmes, comprising the Master of Music, the MA in Classical and Contemporary Text, the MA in Musical Theatre, and a suite of PGCert programmes in the area of learning and teaching. There were some internal and external drivers that we needed to consider: in particular, the concerns suggested above about a possibly over-narrow focus of the music programmes, and a parallel desire on the part of the institution to attempt to foster more in the way of interdisciplinary collaboration among our postgraduate cohort.

On the latter point, it must be realized that the conservatoire takes pride in its unique position as the only UK institution of its type that encompasses a full range of performing disciplines: drama, dance, production, screen and music. In 2006/7, the conservatoire undertook a process of curriculum reform that succeeded in locating interdisciplinary collaboration explicitly within the undergraduate programmes, and there was now an ambition to bring this strategy to the taught postgraduate offerings.

During the 2013 review, it was this confluence of ideas that led to the concept of 'critical artistry', made concrete in a ten-credit module entitled 'Approaches to Critical Artistry' (ATCA) that is common across all of our master's programmes. What is 'critical artistry'? Thinking was informed by a handbook (Polifonia Working Group, n.d.) on artistic research in higher music education, Perspectives on 2nd Cycle Programmes in Higher Music Education, which claims that 'Getting the design, delivery and learning ethos of the Masters programme right is arguably the single most important way that conservatoires can ensure that they are ... giving students an appropriate professional training' (Polifonia Working Group, n.d.: 2I).

Critical artistry is a conception whereby students develop new insights and skills that are critically understood within the context of their new experiences, to develop artistic maturity and embrace challenges, which in turn promotes their own artistic identity through continual applied practice (Royal Conservatoire of Scotland, 2014: 257-8).

The central idea is that students are equipped with resilience, innovation and vision, with the potential to support both their long-term professional development and any future engagement with higher level education. Critical artistry ensures new challenges and new contexts are embraced in study, through collaborative working and network development - key skills necessary to a creative practice (Gaunt and Westerlund, 2016).

While articulating a clear philosophy to underpin our taught postgraduate programmes, this single module has not solved all of our problems. There is undoubtedly more coherence between the three performance programmes - music, drama and musical theatre - than previously, with students on these different degrees producing broadly equivalent portfolios of practice research in order to pass the module. These three groups of students are still working mostly independently of one another, with the module only affording a very limited amount of curricular time and space for interdisciplinary collaboration. In the third year of operation of the framework, it has proved necessary to split the postgraduate teaching programmes off into their own version of the ATCA module, with the same philosophy but a different pattern of delivery and assessment that better fits part-time degrees focused on education rather than performance.

This programme development responded to the need for $\mathrm{HE}$ institutions to better prepare graduates for employment, notably by supporting the development of their independent, flexible approach to continued learning and collaboration in new environments.

\section{Learning through digital creativity in higher music education}

It is a familiar mantra that digital technologies enhance, extend and sometimes disrupt learning in the creative sphere: access to information and communication technologies has a clear and significant impact on all our lives. The digital enables the breakdown of hierarchies, boundaries 
and barriers to expression. It has a particularly compelling role in the production, dissemination and consumption of music, and by extension in music education.

The exponential increase of digital capacity inevitably provokes questions for HE around previously held notions of intrinsic and extrinsic uses of technology within music, and around the role of the educator. Before the turn of the century, students arrived in HE expecting to be taught the use of hardware and software, whereas digital natives now tend to enter degree programmes already using a wide range of tools very effectively. Cain (2004) demonstrated that teaching music technology tends to duplicate what students know already from their own practice. Other researchers in pre-HE music education have come to similar conclusions: Field (2007: 156) noted that 'strategies which inspire creativity should be sought in preference to a skills-oriented curriculum. Although a degree of technological literacy is undoubtedly required ... it is not the skills themselves that are important, but how they are acquired.' In an age of increasingly rapid technological change, this versatility and creative confidence becomes ever more significant.

The needs of industry change almost as rapidly and radically as technology itself. Gone is the demand for 'glass wall' music producers and engineers; the terms Tonmeister and 'audio engineer' are now perceived as anachronistic. Consequently, music students in HE now embrace a wide range of digital practices, such as app development, coding, gaming, music production, video production, DJing, VJing and virtual reality. Just as the consumption of music has been radically disrupted, so has its creation and production. Educators now need to focus on the creative process and on a critical engagement with the digital, rather than merely teaching digital skills. Educators now prepare students for work roles that do not yet exist, and which will require tools that are yet to be developed. Indeed, the familiarity with computing facilitated in school environments by products such as Raspberry Pi needs to be further exploited in HE: young learners who work with Code Club will undoubtedly enter HE with more sophisticated digital skills and awareness than previously was the case, in turn creating new opportunities for creative pedagogies. Music students across a wide variety of HE programmes engage with the digital through mediation and re-mediation, and the boundaries between media are increasingly permeable. Graduates need to be multi-skilled and need to engage with the visual just as much as with audio; they must use social media skilfully in order to reach live audiences.

Digital technologies provide clear opportunity for collaboration with other disciplines: students on music programmes at Bath Spa University work with others in areas such as creative computing, creative media practice, web design, publishing, animation, video gaming and audiovisual production. Their digital workflows evolve from processes of ideation that are increasingly shared by all of these areas. A comment from a Level 6 module evaluation on the Creative Music Technology programme in 2015 identifies the resulting collaboration as a high point of the learning experience: 'working with film students has been the best of my course - really gives me an idea of what it's like to be in the industry'. Moreover, there are ever-wider opportunities for co-creation with other cultures. As early as 2006, school projects exploited these very effectively, as shown by Seddon, who explored relationships between instrumental tuition and composition between the UK and Norway (Seddon, 2006). Recent increases in bandwidth and internet speeds enable greater capacity, and students now occupy an important virtual creative 'habitus' (Bourdieu, 1993), which enables them to co-create with students across the world. Bath Spa University has transnational relationships with institutions in China, Australia and Spain that are fuelled by digital collaboration. Songwriters work with producers and performers online, performers commission composers online and students pursue enterprise projects online. Such creative collaboration is facilitated by distance learning, with some synchronous and much asynchronous work, using cloud computing along industrial models of practice. The Online Orchestra project (involving the Arts and Humanities Research 
Council, Falmouth University, the University of Bristol, Cornwall Music Education Hub and the Philharmonia) is an example of a digital project that required $\mathrm{HE}$ input but also has widespread social and community benefits. It set out to discover how network technologies and creative approaches to composition might be used towards the democratic ideal of collaborative performance opportunities for communities who would not otherwise have access to these.

Facilitation of creative work may involve the deliberate subversion of technology: Keep (2013) has coined the term 'wrong Pro Tools', where students are encouraged to stretch software to creative extremes and to 'break' conventions where unconventional means are justified by aesthetic ends (as a digital parallel to Jimi Hendrix's creative use of feedback). For Keep, an assessment item may:

invite students to explore the hidden sound world of digital sonic artefacts, go beyond the training manual, and work against the recommended use of plug-ins and editing features. The notion and aesthetic of wrongness is a springboard to deliberately seek and exploit digital errors ... as the basis for a self-contained synthesis, sound design, processing and compositional environment.

(Keep, 2013: n.p.)

Students in HE music use technology in areas where it may not traditionally have featured: for example, acoustic performers and composers increasingly work with interactive music software (such as MAX/MSP/Jitter) to create performances and installations. Interactive MIDI hardware such as Soundbeam is used widely in special needs education projects, where ultrasound and tangible inputs generate MIDI messages, with significant impact on the provision of community arts programmes.

Thus, we need to re-conceptualize and integrate technology and the digital within music education. We need to move away from notions of specialist boundaries to an arena in which music graduates are multi-skilled and have the courage of their creativities to work with future technologies as yet unknown in a transformative way. We must acknowledge that students (whether we agree with the concept of 'digital natives' or not) are more likely to be engaged with technology and conversant with the digital than ever before by the time they reach us, and we need to adapt our curriculum and pedagogies accordingly. We must acknowledge the realities of the industrial contexts that our graduates face: NESTA reports that 'the part of the workforce which straddles both the creative and high-tech economies (industries) has been particularly dynamic over this period [20II-13], growing at 8.0 per cent ( 9.6 per cent) p.a.' (Bakhshi et al., 20I5: 56). This points to a continuing trend towards the intersection of digital and creative skills in the economy. This is reflected in the Creative Industries Council's Create Together strategy document by the recommendation that industry-HE strategic partnerships should be nurtured in the creative industries (CIC, 2016: 16). We must loosen our framing of technology within $\mathrm{HE}$ in order to free ourselves up to make the most of what it offers to us and to our students, most particularly in terms of democratization, inclusion and gender.

\section{Creativities, music careers, gender and the case for institutional change}

When professional musicians are asked how they think their gender affected their working lives, there is significant variance in the extent to which women see their gender as always and inevitably relevant. This response is related to the issue of why women are not always regarded as equals in music creativities, leadership and action. To imagine and develop new collaborative worlds is an aspect of diverse creativity, yet the importance of the multiple creativities and 'ample opportunities for the deliberate production of insights' (Gaunt and Westerlund, 2016: 2I) that provide the driving force for professional musicians in preparing them for the professional worlds they must navigate is largely unrecognized. 
Without doubt, gender affects how colleagues and society in general view men and women. Students enter the academy having already been exposed to messages about their gender from their parents, schooling and wider society. People are affected by a wide range of gender messages: these run the gamut from positive and empowering through to inhibiting and undermining. When women, in particular, join the workplace as professional musicians, their sense of what it is acceptable and unacceptable for them to be and become is dramatically shaped by their working environment and interactions with colleagues. When gendered signification, positioning and the place of women within the dominant discourses is linked to the 'takenfor-granted' discourses and practices of diverse creativities, a sense of unfairness and inequity becomes clear both within and without the academy.

Drawing from a study of early career music professionals (Burnard, 20I2), the following quotation from a singer-songwriter articulates the significance of an institutional gendered influence over and above the direct impact of family background:

It was when I went to music college that creativity started playing a role in my playing and
interpretations of pieces. I started having lessons from a world-class pianist. ... my teacher
rightly told me that 'You're not bad. Look, you're even musical, and you got into in the college,
OK because you're musically creative, but you don't really have much technique, and if you
really want to make it as a pianist you need to practise for six hours a day, and you need to do
your scales, and you need to do this, and you need to do that.' OK, so I wasn't a child prodigy
who'd played a piece l'd composed myself at six years old with hands like Liszt! I had a go at it
for about a year, but this routine and regime of becoming a technically brilliant musician takes
so much practice and this wasn't for me really. It was very solitary. I didn't feel it was creative.
While I felt there was potential for creativity, in the end, what I had to do in that moment wasn't
creative at all, it was very much purely technique-based stuff ... I spent a whole year working up
a Chopin piece and others like that, I can't even contemplate or picture that now. I've come to
understand l'd missed getting the kind of rigorous training which people need to have if they're
going to become classical players and go on to be a world-class concert pianist. So I changed to
composition in my second year, because I thought that would be more creative. But in a way
that too had its own dogma.

(Burnard, 2012: 88)

In a similar vein, the claim that creating new work in Western art music is associated with an inspired individual - usually a genius composer - sitting at the piano in his study painstakingly moulding, or divinely pouring, musical ideas into a masterwork, or that the instrumentalist/singer requires instrumental/vocal virtuosity to make it as a performer, are specific manifestations of myths in music, myths about music and gendered myths about music's production. Key to these beliefs is the role played by institutions, which impacts directly on students' secondary and higher education destinations through the quality and quantity of subject and career creativities advice provided in music, and the general ironies of gender and the stereotyping of female artists in society (Bennett and Burnard, 2016). In discussing women's music and female composers (the equivalent term 'male composers' is never seen), contemporary reviewers make continued use of gender stereotypes, as society in general does, with telling use of vocabulary, such as described by Pasler (2008) as 'the ironies of gender' and voiced by this female composer:

There are some major effects of socialization from which you get so many messages; you can easily lose contact with your own specific individual creativity ... there's even more pressure now with new media and technologies which is about moving away from the highly individual, with an overriding message about conforming to a utilitarian, economically driven view of things ... society is a very big teacher. 
Female composers, as with female drummers, are aware of themselves as members of three distinct social groups: (I) being composers or drummers, (2) being females; and (3) being female composers or drummers. The intersection of the meta-identities of composer or drummer and female/feminine (gendered female) brings about the realization of 'female drummer' as an identity. Whereas being a male composer or male drummer is 'statistically and culturally, synonymous with 'drummer' (see the chapter on 'Gender and drumming' in Smith, 20I3: 14I).

To nurture diverse career creativities, music institutions need to be contemporary environments in which creativities are embedded, cultivated, modelled and resourced. We might regard the historical legacy of creativity as being about domain-specific musical processes, products and people, but, as will be argued, a central ingredient in successful institutions is leadership. Music institutions have academic hierarchies of knowledge in which leaders make decisions about people, programmes, practices, performance specialism and professionalism at a high level of complexity, and under great pressure, to demonstrate world-class excellence and global reach. Often, little space is given to diverse voices that counter entrenched gender (and class) biases in academia, or that challenge academic conventions.

Studies that report on creative work, gender constructions, gender representations of creative work, gender role models, career trajectories and how gender is performed in diverse creativities are an imperative (see Burnard, 20I2; Burnard, 20I4). In a recent report that was developed from a programme of research commissioned by NAMHE, gender issues were examined in higher music education departments, schools and institutions. Findings reported that the gendering of roles, disciplines, practices and behaviours plays a big part in music, resulting in the under-representation of women in many areas, particularly at management and policymaking levels. Furthermore, it confirms the existence of cultural and attitudinal barriers faced by many women throughout their careers, despite the existing employment policies, practices and procedures that aim to ensure equality and diversity (Bogdanovic, 20I5).

Neither context nor discourse is static. The perpetuation of gendered creative work is a discourse over which academic institutions exercise influence and power. The underrepresentation and the subordination of women in the music profession is linked to an interrelated set of gender dimensions: power relations, production relations and social embodiment (Connell and Messerschmidt, 2005). We see power relations play out in hierarchical patterns. We see production relations in terms of division of labour and how gender is embodied in musical actions and interactions in ways articulated by this young performing artist:

I was always seen and identified as a 'classical musician' who had got lost ... my experience of doing music at university is peppered with painful scenarios ... I was always put together in tricky ensembles ... I had to work with a drummer who was second study, so he wasn't fantastic on drums and insisted on playing just ska and reggae. The guy on guitar just wanted to play soul and $R \& B$ and the other guy, who was a guitar player wanted to play metal. I felt like I was caught in the middle of a genre war with 18-year-old lads who seemed set in their ways ... They all came in with different dress styling, saying 'this is the sound of me'. ... I recognized in that session that all I wanted to do was to prove to them that I could sing and play my instrument and I would stick up for myself, but in a nice way, without destroying their egos. ... how you define yourself is relative to why and to whom...

(Burnard, 2012: 80-2)

So, how can institutions inspire, embody and accelerate change in stereotypically gendered views, such as whether women can be great composers, conductors or record producers?

Unsurprisingly, the discourses that interrogate the white, male, middle-class hegemony are largely absent from higher music education. We need to understand where inequalities are perpetuated by structures, networks and gendered positioning in and across fields that do 
not allow women access or offer role models. What are the gendered creativities inscribed in the practices of professional musicians? How does gender contribute to or/and restrict music undergraduates' and graduates' musical actions and interactions? What are the gender-related issues that impact on authorial practices in, and principles of, diverse creativities? What can we learn from the training of musicians?

The critical challenges facing music institutions in the education and training of musicians today are issues that preoccupy educators, particularly in higher music education institutions, where there are strong continuities between past and present practices. Music institutions need creativities instigated by their leadership and supported by their management that are integrated with the institution's programmes, practices and administration, and that result in realized actions. The diversity and extent of empathic creativities (Cross et al., 20I2) and intercultural creativities (Saether et al., 2012), to name just two that can be brought to bear, and the magnitude of the consequences, will depend on how gender is performed and 'realized', rather than on the 'intended' creativities that are strategized and implemented by the institution.

Whether formally or informally, it is important to recognize that practically everything we accomplish happens through communal creativities, which involve a nexus of collective choice and professional judgement (Lapidaki et al., 2012). We are not on our own. We are more often working with others in the application of novel ideas for improving the quality of our work, and transforming institutional programme curricula by creative teaching for creative learning in higher academic music education (Haddon and Burnard, 2016), and allowing women from all classes of society the possibility of a bright pluralistic future as professional musicians.

And so, the question is asked: how can we imagine and then invent institutional change? If what it is to be successful is to recognize and harness diverse creativities, our own and those of our colleagues and our students, then we need to continually adapt and invent creativities for accomplishing complex institutional change in an ever-changing and increasingly inequitable world. Yet, we have only begun to think beyond collapsing the uncertainty of institutional habits and perpetuating mindsets. So, how to change practices?

\section{The potential of an integrated student experience}

What is an integrated student experience and what could it accomplish? By the time students reach higher education they have been accustomed to being passive receivers and memorizers of information, and although 'questioning the source' or going beyond what is presented and becoming 'active' learners is encouraged in the secondary curriculum prior to HE in the UK (Broadbent and Grocott, 2013: 3), with pressures to make sure students pass vital exams, both students and teachers are finding themselves in a race towards a finish line of ticking boxes. According to the Secret Teacher, an anonymous blog for The Guardian, 'my students are bright, engaged and well-behaved, but there is something missing: they cannot think' (The Secret Teacher, 2015: n.p.). When discussing how students were hesitant to make a move unless provided with proof that it will assist them in passing their exams, the teacher commented:

It is no wonder this is all students care about because this is all they are conditioned to care about ... It cannot be said enough that we should teach students to think, not just to learn the syllabus. All they want is to follow the rulebook and pass exams.

(The Secret Teacher, 2015: n.p.)

But what can encourage active student engagement? One can argue that students not only need to get involved in the world around them, they particularly need to know how and why they need to get involved. Opportunities to seek things out need to be provided, nurtured and encouraged, and this needs to begin as soon as possible as part of their overall student experience. 
Simone Krüger discusses the importance of research-led education during undergraduate years, saying 'undergraduate research shifts students away from being passive recipients of knowledge and towards active seekers and producers of knowledge' (Krüger, 20I5: I). Among other things, she lists employability, more of a drive to continue education and 'independent self-directed manifestations of music' (Krüger, 20I5: I) as benefits of such awareness and active engagement with knowledge. She describes it as 'learning in the field', and quotes Brew (2007, in Krüger, 2015: I): 'research and inquiry is not just for those who choose to pursue an academic career. It is central to professional life in the twenty-first century.' The more students are aware of how they fit into the world around them, the more likely they are to get involved and pursue opportunities. This awareness of an active collaborative practice (as at the heart of the recent work of Gaunt and Westerlund (2016)) gives students a sense of belonging and ownership over their own learning.

Incorporating social media and media literacy for all students across disciplines is another essential element that can provide students with a much more active student experience. This provides them with the appropriate skills and equal opportunity to critically examine, analyse, evaluate and reflect upon media in all its forms, allowing students the opportunity to interpret and respond to media and become active participants rather than passive consumers.

'[E]verything a student does at an institution, both inside and outside the classroom supports (or opposes) the process of learning' (Wilhite and Banset, 1998-9: 2). Wilhite and Banset explore the possibility of tapping into the 'unintentional learning that occurs outside the classroom' (Wilhite and Banset, 1998-9: 2) in order to enrich the student experience by giving several specific examples on how to do so through different activities. In more recent years, with the growing popularity of social media, bringing this technology into the classroom could on its own potentially break down barriers between educators and students.

Supporting students through social media, especially through mobile devices, can be beneficial to them as learners, performers or creators of music. Research conducted by Nedungadi and Raman 'resulted in a cloud-based adaptive learning system that incorporates mobile devices into a classroom setting' (2012: 659). When discussing 'personalisation in mobile learning', Nedungadi and Raman examine two 'adaptive approaches' presented by Kinshuk et al. in 2009: one approach 'adapts to the learner', and the other 'adapts to the learner's surroundings' (Kinshuk et al. as quoted in Nedungadi and Raman, 2012: 66I). By integrating the use of smartphones and tablets in a much more personalized approach, and incorporating social media as part of learning, students may be much more willing to continue their education outside the classroom by using the same tools they may not have considered educational before their introduction into classroom learning.

A study was conducted at Liverpool Hope University that included a questionnaire sent to six students: two third-year undergraduate students, two postgraduate taught students and two postgraduate research students. The questionnaire tackled employment worries, university-led or encouraged opportunities, online presence and social media within the curriculum.

When asked if they were worried about finding employment in the music field in the future, four out of six responded by saying they were worried for several reasons, one mentioning music as 'not the most secure field of steady employment', and the remaining three mentioning the decline of the arts in the curriculum as a worry when thinking of future employment. The remaining two $\mathrm{PhD}$ students mentioned that they were aware that employment required the right timing and qualifications required for university teaching, and were not necessarily worried about finding employment in the future. Student A wrote: 'Perhaps a monthly lecture should be allocated in order to make students aware of the possibilities of promotion of one's music in the professional music industry.' Student B wrote: 'University life has given me a good idea of what to expect after university providing you only want to be an academic. If you want to 
venture out of academia ... then university isn't equipped to inform its student[s] of what to expect in this field.'

In terms of online presence, five out of six students confirmed that social media education should be part of a music degree, whereas one student was sceptical because of the constantly changing nature of social media, stating that 'good advice is hard to find'. One student noted, 'I think having a professional online presence is absolutely vital for musicians and the music degree could definitely spend some time teaching students how to use social networking in a mature way.' Student $C$ observed: 'because it's 2016 and social media is a huge part of most facets of our lives, it seems remiss not to include discussions about professionalism and social media for any type of degree.'

Along with opportunity, media literacy, and the incorporation of social media into the classroom, gender and cultural awareness can also offer students a much more 'awakened' sense of the world around them as students and members of society. One can argue that a student who is aware is one who is capable of creating the most change. At only 17 years old, Jessy McCabe made history last year as the student who created a petition that led to the inclusion of female composers in the A level Edexcel music curriculum. This petition went viral, gaining thousands of supporters from fellow students, teachers, lecturers and composers, and coverage from publications such as The Guardian and The Independent. When McCabe was asked why she created this petition, she mentioned that she was inspired to take action after taking part in a Fearless Futures leadership programme, an organization that, according to their website, 'organises innovative leadership development programmes for girls and young women with peer-power at their core to point out and potentially change gender injustice' (www. fearlessfutures.org).

Awareness of what it means to be a music student in the twenty-first century, be it from the perspective of media literacy, technology in the classroom, the potential to create change within educational practice, or what a music career in the future may look like, are all examples of what potentially could constitute part of an integrated student experience, within and beyond the classroom.

\section{Concluding thoughts on changing practices in constructing curricula in higher music education}

NAMHE has mapped and responded to the trends in HE music, notably through its conference themes, which are chosen to represent the burning issue of the year. Themes have recently consisted of: 'Snakes and Ladders: Negotiating the TEF landscape', which explored critical questions concerning music and TEF (2017, Cambridge University); 'Practice - Research Policy', which explored the Research Excellence Framework and research impact (2016, Royal Northern College of Music); 'Music - Learning - Technology', which raised questions about how we use social media, online curation and digital creativities within HE music (20I5, Royal Conservatoire of Scotland); 'Learning Communities: Co-Creating vision and sharing practice in higher music education', which sought to explore using student partners and student-led projects to advance the music curriculum (20I4, Bath Spa University); 'Great Expectations: Managing the present', which advocated for the value of music in HEs, with break-out groups acting as a war council to tackle difficult questions concerning the cost of a music degree (2013, Birmingham University); 'The Research Excellence Framework', which explored issues of practice-led research (2012, Manchester Metropolitan University) and 'Education, Employability and skills post-browne', which presented case studies and debates about how we embed employability skills in the curriculum (201 I, Kingston University). 
In putting forward our collective response to some of the issues we have identified, NAMHE has commissioned research on the gender equality mark, as well as presented case study research both at conferences and in consultation documents. Our collection of case studies here represents some of the issues addressed, and actions taken, in particular departments, to demonstrate ways in which mindsets have changed within particular courses, with positive benefits for students and staff.

NAMHE has sought to advocate for the value of a music degree, and celebrate and protect the diversity of the discipline through research projects, video projects, presentations and publications. The executive committee here share these five case studies as exemplars of some of the challenges and opportunities facing music in HE. The shared issue in these case studies in music in HE concerns a reassessment of the curriculum, in terms of diverse creativities, which specifically refer to digital creativities, the representation of diverse racial and gender identities through inclusive curricula, and employability. Each case study presents a new approach to constructing the music curriculum to enhance the student experience. Ensuring such enhancements, which are relevant to the creative industries, is vital to supporting our students towards graduate employment. With the future attention on teaching quality (TEF), and recognition of the student experience, it is a prime time to share areas of good practice and changing ways of doing things with a firm emphasis, as above, on the student voice.

\section{Notes on the contributors}

Helen Julia Minors is Associate Professor of Music and Head of Department of Music at Kingston University, London. She is currently the elected chair of the National Association for Music in Higher Education. She has published widely, including Music, Text and Translation (Bloomsbury, 20I3), and chapters in Erik Satie: Music, art and literature (Ashgate, 20I3), The Routledge International Handbook of Intercultural Arts Research (Routledge, 2016) and Historical Interplay in French Music and Culture (Routledge, 2017).

Pamela Burnard is Professor of Arts, Creativities and Education at the Faculty of Education, University of Cambridge. She convenes the British Educational Research Association (BERA) Special Interest Group, Creativities in Education (www.bera.ac.uk/group/creativity-in-education), and the biennial international conference, Building Interdisciplinary Bridges Across Cultures and Creativities (www.BIBACC.org). She is an international authority on creativities research and has published widely on creative teaching and learning, and the expanded conceptualization of diverse creativities across education sectors and creative industries.

Charles Wiffen is Assistant Dean of the College of Liberal Arts at Bath Spa University and Visiting Professor of Music at Shanghai University. He previously lectured at the Royal College of Music, where he was Grove Research Fellow from 1998 to 2004, and at Trinity Laban in London. Charles has performed extensively as a pianist throughout the UK, as well as further afield in France, Spain, Italy, Belgium, Germany, the USA, Israel, China, Taiwan and Japan, and in Africa.

Zaina Shihabi is a PhD researcher at Liverpool Hope University. After receiving her BA in mass communication in the UAE, Zaina moved to the UK to pursue a career in academia and completed an MA in education and music with distinction. Her current research focuses on the education of the history of music, curriculum development, gender and identity. She is the NAMHE student representative.

J. Simon van der Walt is a composer, performing artist and educator. As an artist he has created a varied body of work, ranging from score-based composition to installation, sound art, 
performance and devised musiktheatre. Current preoccupations include Indonesian gamelan and livecoding. He is Head of MMus Programmes at the Royal Conservatoire of Scotland. He is former Scotland representative on the committee of the National Association for Music in Higher Education.

\section{References}

Auslander, P. (1999) Liveness: Performance in a mediatized culture. London: Routledge.

Back, L. and Puwar, N. (eds) (2012) Live Methods. Malden, MA: Wiley-Blackwell.

Bakhshi, H., Davies, J., Freeman, A. and Higgs, P. (2015) The Geography of the UK's Creative and High-Tech Economies. London: Nesta. Online. www.nesta.org.uk/sites/default/files/geography_uks_creative_ high-tech_economieswv20I5I.pdf (accessed 29 July 2017).

Bennett, D. and Burnard, P. (2016) 'Human capital career creativities for creative industries work: Lessons underpinned by Bourdieu's tools for thinking'. In Comunian, R. and Gilmore, A. (eds) Higher Education and the Creative Economy: Beyond the campus. London: Routledge, 123-42.

Berry, J. and Loke, G. (20I I) Improving the Degree Attainment of Black and Minority Ethnic Students. London: Equality Challenge Unit/HEA. Online. www.ecu.ac.uk/wp-content/uploads/external/improving-degreeattainment-bme.pdf (accessed 20 November 2016).

Bogdanovic, D. (2015) Gender and Equality in Music Higher Education. National Association for Music in Higher Education. Online. www.namhe.ac.uk/publications/reports/gender_and_equality_2015.pdf (accessed 29 July 2017).

Bourdieu, P. (1993) The Field of Cultural Production. Cambridge: Polity Press.

Broadbent, D., and Grocott, R. (eds) (2013) GCSE History: Modern world history complete revision \& practice. Kirkby in Furness: Coordination Group Publications.

Burnard, P. (2012) Musical Creativities in Practice. Oxford: Oxford University Press.

Burnard, P. (ed.) (2014) Developing Creativities in Higher Music Education: International perspectives and practices. London: Routledge.

Cain, T. (2004) 'Theory, technology and the music curriculum'. British Journal of Music Education, 2I (2), $215-2 \mid$.

CIC (Creative Industries Council) (2016) 'Create Together'. Online. www.thecreativeindustries.co.uk/ resources/strategy (accessed 29 July 2017).

Connell, R.W. and Messerschmidt, J.W. (2005) 'Hegemonic masculinity: Rethinking the concept'. Gender and Society, 19 (6), 829-59.

Cross, I., Laurence, F. and Rabinowitch, T.-C. (2012) 'Empathy and creativity in group musical practices: Towards a concept of empathic creativity'. In McPherson, G.E. and Welch, G.F. (eds) The Oxford Handbook of Music Education (Vol. 2). New York: Oxford University Press, 337-53.

Field, A. (2007) 'New forms of composition, and how to enable them'. In Finney, J. and Burnard, P. (eds) Music Education with Digital Technology. London: Continuum, 156-68.

Gaunt, H. and Westerlund, H. (eds) (2016) Collaborative Learning in Higher Music Education. London: Routledge.

Haddon, E. and Burnard, P. (eds) (2016) Creative Teaching for Creative Learning in Higher Music Education. London: Routledge.

HEFCE (Higher Education Funding Council for England) (n.d.) 'The Teaching Excellence Framework'. Online. www.hefce.ac.uk/lt/tef/ (accessed 20 April 2017).

Hussain, M. (2015) 'Why is my curriculum white?'. NUS News, I I March. Online. www.nus.org.uk/en/news/ why-is-my-curriculum-white/ (accessed 20 November 2016).

Keep, A. (20/3) 'Wrong Pro Tools: A pedagogical tool for sonic experimentation'. Paper presented at the 'From Tape to Typedef: Compositional methods in electroacoustic music' conference, University of Sheffield, 30 January-2 February 2013.

Kingston University (2016) 'BME attainment gap institutional KPI'. Online. www.kingston.ac.uk/ aboutkingstonuniversity/equality-diversity-and-inclusion/bme-attainment-gap/ (accessed 20 April 2017). 
Kingston University (2016a) 'Developing an Inclusive Curriculum'. Online video. https://youtu.be/ wbjAsDjZRD0 (accessed 20 October 2016).

Kingston University (2016b) 'Excellence Framework for an Inclusive Curriculum'. Online video. https:// youtu.be/YULZELyHgnk (accessed 20 October 2016).

Kingston University (2016c) 'Excellence Framework for an Inclusive Curriculum - Part 2'. Online video. https://youtu.be/eLhOVaTyRak (accessed 20 October 2016).

Kingston University (2017) 'Inclusive Curriculum Case Studies'. Online video. www.youtube.com/ watch? $=K Z$ Z6CKQCcqc (accessed 20 April 2017).

Kinshuk, Chang, M., Graf, S. and Yang, G. (2009) 'Adaptivity and personalization in mobile learning'. Paper presented at the AERA Annual Meeting, San Diego, CA, 13-17 April, 2009. Online. http://sgraf. athabascau.ca/publications/kinshuk_etal_AERA09.pdf (accessed 8 September 2017).

Krüger, S. (2015) 'Embedding student research in the undergraduate curriculum: Learning in the field'. Paper presented at the Teaching and Learning Conference, Liverpool John Moores University, 17-18 June 2015. Online. http://researchonline.ljmu.ac.uk/I622/I/Paper\%28May\%2020I5\%29_Embedding\%20 Student\%20Research\%20in\%20the\%20Undergraduate\%20Curriculum.pdf (accessed 29 July 2017).

Lapidaki, E., de Groot, R. and Stagkos, P. (2012) 'Communal creativity as socio-musical practice'. In McPherson, G.E. and Welch, G.F. (eds) The Oxford Handbook of Music Education (Vol. 2). New York: Oxford University Press, 37I-88.

Minors, H.J., Burnard, P., Shihabi, Z. and Wiffen, C. (2016) 'Mapping Trends and Framing Issues in Higher Music Education: Changing minds/challenging practices'. Panel session papers presented at the International Society for Music Education (ISME) 32nd World Conference, Glasgow, 25-29 July 2016.

Morgan, W. (2016) 'Why is my professor still not black?'. Times Higher Education, I 4 March. Online. www. timeshighereducation.com/blog/why-my-professor-still-not-black (accessed 20 November 2016).

Mountford-Zimdars, A., Sabri, D., Moore, J., Sanders, J., Jones, S. and Higham, L. (2015) Causes of Differences in Student Outcomes. London: HEFCE. Online. www.hefce.ac.uk/media/HEFCE,20I4/Content/Pubs/ Independentresearch/2015/Causes, of,differences, in,student,outcomes/HEFCE20 I5_diffout.pdf (accessed 20 November 2016).

Musicians' Union (2012) The Working Musician. London: DHA Communications. Online. www. musiciansunion.org.uk/Files/Reports/Industry/The-Working-Musician-report (accessed 12 October 2016).

NAMHE (National Association for Music in Higher Education) (2015-16) 'Value of a Music Degree'. Video project. Online. https://vimeo.com/namhe (accessed October 2016).

Nedungadi, P. and Raman, R. (2012) 'A new approach to personalization: Integrating e-learning and m-learning'. Educational Technology Research and Development, 60 (4), 659-78.

Pasler, J. (2008) Writing through Music: Essays on music, culture, and politics. New York: Oxford University Press.

Polifonia Working Group on Artistic Research in Higher Music Education (n.d.) Perspectives on 2nd Cycle Programmes in Higher Music Education. Brussels: Association Européenne des Conservatoires. Online. www.aec-music.eu/userfiles/File/Polifonia/VI50424\%200nline\%20EN\%20WG2.pdf (accessed 29 July 2017).

Puwar, N. (2004) Space Invaders: Race, gender and bodies out of place. Oxford: Berg.

RMA (Royal Musical Association) (2016a) 'Current issues in HE: NAMHE-convened roundtable discussion from the RMA Research Students' Conference, University of Bangor, January 2016 - Part I'. RMA Student Blog, 15 March. Online. www.rma.ac.uk/students/? $p=2772$ (accessed 29 July 2017).

RMA (Royal Musical Association) (2016b) 'Current issues in HE: NAMHE-convened roundtable discussion from the RMA Research Students' Conference, University of Bangor, January 2016 - Part II'. RMA Student Blog, 2 I March. Online. www.rma.ac.uk/students/? $p=2774$ (accessed 29 July 2017).

RMA (Royal Musical Association) (2016c) 'Current issues in HE: NAMHE-convened roundtable discussion from the RMA Research Students' Conference, University of Bangor, January 2016 - Part III'. RMA Student Blog, 25 March. Online. www.rma.ac.uk/students/?p=2822 (accessed 29 July 2017).

RMA (Royal Musical Association) (2016d) 'Current issues in HE: NAMHE-convened roundtable discussion from the RMA Research Students' Conference, University of Bangor, January 2016 - Part IV'. RMA Student Blog, 5 April. Online. www.rma.ac.uk/students/?p=2824 (accessed 29 July 2017). 
RMA (Royal Musical Association) (2016e) 'Current issues in HE: NAMHE-convened roundtable discussion from the RMA Research Students' Conference, University of Bangor, January 2016 - Part V'. RMA Student Blog, II April. Online. www.rma.ac.uk/students/?p=2855 (accessed 29 July 2017).

Royal Conservatoire of Scotland (2014) MMus/MA Programme Handbook 20/4/2015. Glasgow: Royal Conservatoire of Scotland.

Royal Conservatoire of Scotland (2016) Prospectus 2017/2018. Glasgow: Royal Conservatoire of Scotland. Saether, E., Mbye, A. and Shayesteh, R. (20I2) 'Intercultural tensions and creativity in music'. In McPherson, G.E. and Welch, G.F. (eds) The Oxford Handbook of Music Education (Vol. 2). New York: Oxford University Press, 354-70.

The Secret Teacher (2015) 'Exams have left my students incapable of thinking'. The Guardian, 7 February. Online. www.theguardian.com/teacher-network/20I5/feb/07/secret-teacher-exams-students-thinking (accessed 29 July 2017).

Seddon, F.A. (2006) 'Collaborative computer-mediated music composition in cyberspace'. British Journal of Music Education, 23 (3), 273-83.

Smith, G.D. (2013) I Drum, Therefore I Am: Being and becoming a drummer. Farnham: Ashgate.

Taylor, P. (20I5) 'Mozart in Madrās: Global learning and Western art music'. Musica Docta: Rivista digitale di Pedagogia e Didattica della musica, 5, II3-25.

Wilhite, M. and Banset, L. (1998-9) 'Learning outside the box: Making connections between co-curricular activities and the curriculum'. Essays on Teaching Excellence: Toward the Best in the Academy, I0 (5), I-6. Online. http://podnetwork.org/content/uploads/VI0-N5-Wilhite_Banset.pdf (accessed 29 July 2017).

\section{Related articles published in the London Review of Education}

The paper was published in a special feature of the journal called: 'Music education in context', edited by Hilary McQueen and Maria Varvarigou. The other articles in the feature are:

Black, P. (2017) 'On being and becoming a jazz musician: Perceptions of young Scottish musicians'. London Review of Education, 15 (3), 339-57.

Cooper, N. (2017) 'Design-based research as an informal learning model for choral conductors'. London Review of Education, 15 (3), 358-71.

Gande, A. and Kruse-Weber, S. (2017) 'Addressing new challenges for a community music project in the context of higher music education: A conceptual framework'. London Review of Education, 15 (3), $372-87$.

Hallam, S. (2017) 'The impact of making music on aural perception and language skills: A research synthesis'. London Review of Education, 15 (3), 388-406.

Hart, A. (2017) 'Towards an effective freeware resource for music composition in the primary classroom'. London Review of Education, 15 (3), 407-24.

Holmes, S. and Hallam, S. (2017) 'The impact of participation in music on learning mathematics'. London Review of Education, 15 (3), 425-38.

Johnson, C. (2017) 'Teaching music online: Changing pedagogical approach when moving to the online environment'. London Review of Education, 15 (3), 439-56.

Rodgers, D. (2017) 'Community music as a vehicle for tackling mental health-related stigma'. London Review of Education, 15 (3), 474-87.

Sarazin, M. (2017) 'Can student interdependence be experienced negatively in collective music education programmes? A contextual approach'. London Review of Education, 15 (3), 488-504. 